\title{
Remote Sensing of Land Surface Phenology
}

Phenology is the study of periodic life-cycle events (for example, flowering, insect emergence, nesting, migration) and how these stages are affected by climate and environment. Phenology describes how organisms are specifically adapted to the environmental cycles that surround them and it applies to nearly all aspects of life on Earth including the abundance, distribution, and diversity of organisms, ecosystem services, food webs, and the global cycles of water and carbon. Phenological events are sensitive to climate variation; therefore, phenology data provide important baseline informa- tion documenting trends in ecology and detecting the impacts of climate change on ecosystems at multiple scales.

Remote sensing of land-surface phenology can characterize vegetation changes during the growing season and documents specific events such as start and end of season and growing season duration (table 1). These indicators can reveal broad-scale phenological trends that are difficult to detect over large areas using traditional ground-based methods (fig. 1). Remote Sensing Phenology indicators developed by the U.S. Geological Survey (USGS) RSP program are used

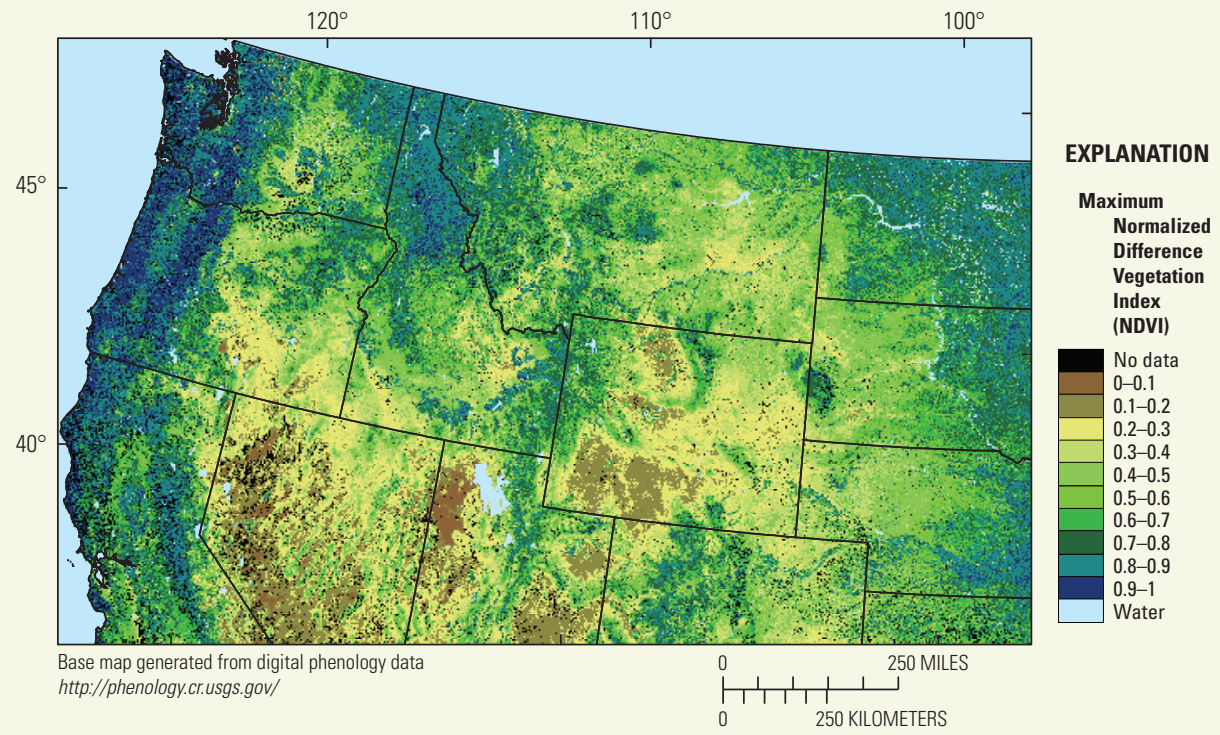

Figure 1. Example of a phenology indicator. The indicator shown is maximum Normalized Difference Vegetation Index (NDVI) and can be used to estimate peak canopy photosynthetic activity during the growing season.

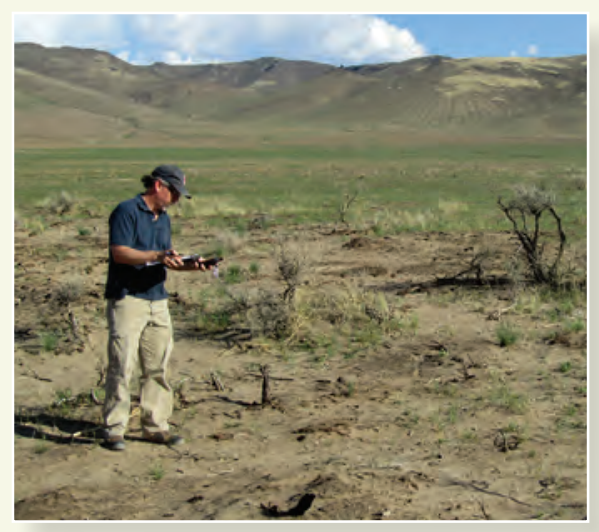

Figure 2. A U.S. Geological Survey scientist records ground data that are used (along with other datasets) with start of season phenology indicator to model cheatgrass (Bromus tectorum) growth in the Northern Great Basin (photograph by Matthew Rigge, USGS).

by government agencies, universities, and conservation groups, among others, to model the growth of noxious weeds, assess forage production, characterize climate and phenology interactions, and model fire potential (fig. 2).

Land-surface phenology indicators developed by the USGS RSP program are derived from the Normalized Difference Vegetation Index (NDVI) and are processed to highlight vegetation changes. Nine phenology indicators are available at 250-meter and 1,000-meter resolution, and can be downloaded from http:// phenology.cr.usgs.gov/index.php (table 1).

Table 1. Remote sensing phenology data at 250-meter and 1,000-meter resolution available at http://phenology.cr.usgs.gov/index.php .

[NDVI, Normalized Difference Vegetation Index]

\begin{tabular}{lll}
\hline \multicolumn{1}{c}{ Phenology metric } & Acronym & \multicolumn{1}{c}{ Description } \\
\hline Amplitude & AMP & Maximum increase in canopy photosynthetic activity above the baseline. \\
\hline $\begin{array}{l}\text { Duration } \\
\text { End of season NDVI }\end{array}$ & DUR & Length of photosynthetic activity (the growing season). \\
\hline End of season time & EOSN & Level of photosynthetic activity at the end of measurable photosynthesis. \\
\hline Maximum NDVI & EOST & End of measurable photosynthesis in the vegetation canopy. \\
\hline Maximum time & MAXN & Maximum level of photosynthetic activity in the canopy. \\
\hline Start of season NDVI & MAXT & Time of maximum photosynthesis in the canopy. \\
\hline Start of season time & SOSN & Level of photosynthetic activity at the beginning of measurable photosynthesis. \\
\hline Time-integrated NDVI & SOST & Beginning of measurable photosynthesis in the vegetation canopy. \\
\hline
\end{tabular}


"Phenology is an underlying indicator of vegetation change, when it is scaled-up by remote sensing it can show potentially significant changes to populations in both time and space."

$$
\text { -Jake Weltzin, Executive }
$$
Director, USA National Phenology Network
To promote an understanding of how the RSP indicators relate to actual field conditions, the RSP program is collecting on-the-ground phenological data in conjunction with the USA National Phenology Network (USANPN). The USA-NPN promotes a broad understanding of plant and animal phenology and its relationship with environmental change. The network is a consortium of individuals and organizations that collect, share, and use phenology data, models, and related information.



Figure 4. Start of season in the mountains of southwestern Colorado in $A, 2002$ and B, 2007.

\section{References Cited}

Worrall, J.J., Rehfeldt, G.E., Hamann, A., Hogg, E.H., Marchetti, S.B., Michaelian, M., and Gray, L.K., 2013, Recent declines of Populus tremuloides in North America linked to climate: Forest Ecology and Management, v. 299, p. 35-51.

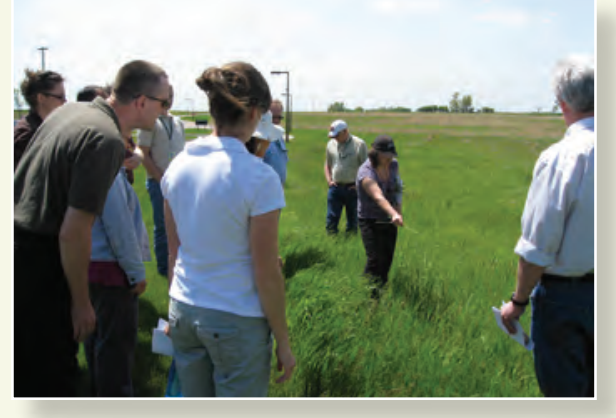

Figure 3. Volunteers at the U.S. Geological Survey Earth Resources Observation and Science Center (USGS EROS) in Sioux Falls, South Dakota, monitor the timing of seasonal events (bud burst, flowering, and leaf drop).

The USGS Earth Resources Observation and Science (EROS) Center is building a record of the vegetation phenology of 14 species around its South Dakota campus using Nature's Notebook (https:// www.usanpn.org/natures_notebook), which is a phenology monitoring program that relies on "citizen scientists" to record plant and animal life-cycle events (fig. 3). These life-cycle data are made available by the USA-NPN to anyone interested in studying the phenology of species in their local areas and the response of species to their environment. These local observations provide important ground data for scientists who study climate and vegetation interactions.

Phenology indicators reveal important environmental data about the vegetation around us. For example, the mountains of southwestern Colorado often receive heavy snow in spring, though 2002 was a remarkably dry spring (Worrall et al., 2013). RSP data were used to show the start of vegetation growth [in a sample area]. Figure 4 compares the 2002 start of season with the 2007 start of season for a sample area in southwestern Colorado. In 2002, the start of season for elevations above 3,000 meters occurred during the last week of March and the first week of April. Whereas, in 2007 the start of season occurred a month later during late April and early May.

\section{For more information contact:}

custserv@usgs.govor

USGS Earth Resources and Observation

Science (EROS) Center

47914 252nd Street

Sioux Falls, SD 57198 